\title{
From the Teachers Perspective: Exploring Ways to Navigate Transformative Dialogues about Microaggressions in Social Work Higher Education
}

\author{
Allen Lipscomb ${ }^{1}$, Wendy Ashley ${ }^{1} \&$ Sarah Mountz $^{2}$ \\ ${ }^{1}$ Social Work Department, California State University Northridge, Northridge, USA \\ ${ }^{2}$ School of Social Welfare, State University of New York, Albany, USA \\ Correspondence: Allen E. Lipscomb, PsyD, MSW, LCSW, Social Work Department, California State University \\ Northridge, 18111 Nordhoff Street, Northridge, CA 91330-8226, USA. Tel: 818-677-7630.
}

Received: August 18, 2017

Accepted: September 12, 2017

Online Published: September 13, 2017

doi:10.5430/irhe.v2n3p50

URL: https://doi.org/10.5430/irhe.v2n3p50

\begin{abstract}
Graduate social work education is a fertile context for microaggression encounters. Because a core concept of the discipline is social justice advocacy, social work pedagogy is steeped with instruction, reading materials, activities and dialogue regarding diversity, intersectionality, oppression, power, and privilege. Students enter graduate school from a plethora of backgrounds, maturity levels, and exposure to justice informed critical thinking. As a result, learning opportunities take place not only in classrooms and field placements, but also in social, interpersonal exchanges. Therefore, it is imperative that social work educators teach academic concepts while modeling and managing the process in which microaggressions proliferate. Drawing from auto-ethnographic data obtained through instructors' observations of microaggressions occurring in social work classrooms, the authors posit that uncontained microaggressions can have a deleterious impact on students, faculty and the larger social work climate outside of higher education. Pedagogical tactics and strategies to navigate the nuances of micro, mezzo and macro microaggressions within the constructs of social work higher education are provided.
\end{abstract}

Keywords: microaggression, social justice, teaching social work, higher education

\section{Introduction}

Universities offer opportunities for academic advancement and personal enrichment. Simultaneously, college campuses and classrooms are often settings for microaggression exchanges, creating a climate where some enjoy a sense of acceptance and entitlement while others face condemnations of being unwelcome and unqualified (Yosso, Smith, Ceja \& Solórzano, 2009). Microaggressions are defined as exchanges that convey subtle insults or denigrating messages to certain individuals because of their membership in a minority or other marginalized group (Sue, 2010; Sue \& Constantine, 2007). While there are many articles that address the impact of microaggressions on college students (Bair \& Steele, 2010; Boysen, 2012; Sue, Lin, Torino, Capodilupo \& Rivera, 2009), there is a dearth of research examining social work education as a cultural context for navigating microaggression dilemmas. Social justice maintains a fundamental role in the core of the discipline, with a value system that advocates for social, economic and political equity for all, especially those vulnerable or in need (National Association of Social Workers (NASW), 2015). As a result, social work curricula and classrooms are infused with instruction, dialogue and application of intersectionality, oppression, power and privilege concepts. Thus, the social work classroom is fertile ground for microaggression encounters.

Difficult dialogues on race, sexual orientation, gender identity and other intersectionality factors represent potentially threatening conversations or interactions between very different groups with differing levels of power and privilege, in addition to being ripe spaces of opportunity (Sue, et al, 2009). Vital to the development of critical thinking skills necessary to navigate through professional interpersonal dilemmas is cultivating a classroom environment where instructors model and engage in discourse that identifies and manages microaggressions. Intergroup dialogue can be utilized to serve as a tool to increase compassion, dispel stereotypes and decrease intergroup hostilities (Sue, et al, 2009). These dialogues provide students with language to articulate how microaggressions are perceived and 
experienced and demonstrate a process in which uncomfortable conversations can occur while maintaining respectful relationships.

Unfortunately, educators frequently struggle with addressing microaggressions in the classroom setting. Watt (2007) described these dialogues as evoking unpleasant emotional "hot buttons", leading many to avoid, ignore or dismiss them as taboo (Sue, et al, 2009, p. 184). However, Sue, et al (2009) found whether difficult dialogue was facilitated or hindered depended on the awareness, skills and knowledge of the instructor. Unaware, uncomfortable professors have the potential to invalidate, devastate or initiate additional microaggressions (Spanierman, Armstrong, Poteat \& Beer, 2006). Instructors that appeared comfortable acknowledging microaggressions validated feelings, exhibited good communication skills and legitimized differing identity realities, providing a valuable learning experience (Sue, et al, 2009).

It is imperative instructors are aware of their influence on how students comprehend and apply academic concepts, and that the larger implications of failing to act are considered. It is critical for professors to take leadership to incorporate a social justice framework into their praxis, both in classrooms and in the field (Brown \& Perry, 2011). Microaggressions experienced within the context of graduate school impact relationships and learning, potentially undermining the short and long term effectiveness of the students and faculty experiencing them. Smith (2004) defines the physical, mental and emotional strain engendered by these assaults over time as "racial battle fatigue." An additional consequence to the field of social work is losing students and faculty representative of the vulnerable, marginalized communities the discipline is charged to empower because they feel alienated from their professional community.

Further, without directly addressing racist, misogynistic, homophobic, transphobic or other microaggressions as they occur in the classroom, are we teaching social work students that only academic content is relevant in becoming an effective social worker? It is a gross misperception that a social work practitioner can be heterosexist, racist or transphobic and also develop genuinely supportive and transformative relationships with gay, lesbian, bisexual, queer, transgender, questioning and clients or communities of color (Brown \& Perry, 2011; Spanierman, Armstrong, Poteat \& Beer, 2006). Therefore, it is essential for social work educators to value, practice and teach students to practice reflexivity, recognizing the bidirectional reciprocity of a therapeutic relationship (Casey, 2011). For social work in particular, these exchanges offer a process for the development of self-awareness, empathy and authenticity.

\section{Literature Review}

The term microaggression was coined by Psychiatrist and Harvard Professor Chester M. Pierce in 1970 to describe the slights and often subtly undermining gestures perpetrated against African-Americans by non-black Americans. He defined microaggressions as “...subtle, stunning, often automatic nonverbal exchanges which are 'put-downs' of blacks by offenders" (Pierce, Carew, Pierce-Gonzales, \& Willis, 1977, pp. 66). In 1973, MIT Economist Mary Rowe, expanded the term to include similarly derogatory gestures enacted towards women. Since this time the concept of microaggressions has been expanded and developed to understand the casual, daily degradation experienced by many socially marginalized groups, including people of color, people with disabilities, women, members of the LGBTQ community, and individuals who live at the intersections of multiple marginalized identities.

Perhaps most famous for his work on racial microaggressions is Columbia educational scholar Derald Wing Sue, who defines microaggressions as "verbal, behavioral, or environmental indignities whether intentional or unintentional, that communicate hostile, derogatory, negative racial slights and insults towards people of other races (Sue, Capodilupo, Torino, Bucceri, Holder, Nadal \& Esquilin, 2007, pp. 271). Sue and his colleagues (2007) developed a taxonomy for understanding various categories of microaggressions that remains widely used today, delineating three primary forms microaggressions may take: 1) microassault: an explicit racial derogation; verbal/nonverbal; e.g.: name-calling, avoidant behavior, purposeful discriminatory actions; 2) microinsult: communications that convey rudeness and insensitivity and demean a person's racial heritage or identity; subtle snubs; unknown to the perpetrator; hidden insulting message to the recipient of color; and 3) -microinvalidation: communications that exclude, negate, or nullify the psychological thoughts, feelings, or experiential reality of a person belonging to a particular group. Microaggression scholarship has also focused on environmental microaggressions, in which microaggressive messaging is embedded in either the built environment or via public policy (Sue, 2010). Contemporary conceptualizations of microaggressions highlight their embeddedness in modern, less covert racist ideologies, namely aversive or colorblind racism. Research regarding racial microaggressions has largely been conducted within clinical and educational contexts, focusing on the nature and impact of microaggressions perpetrated by educators, clinicians, or peers upon students and/or clients of colors. Within a clinical context, Sue has looked at the 
impact of racial microaggressions perpetrated by clinicians upon the therapeutic alliance, with a primary emphasis upon a White clinician-client of color dyadic relationship (Sue, 2008).

Within an educational context, work has focused primarily upon the experiences of undergraduate students of color within educational contexts using focus group and individual interview data. For example, Daniel Solorzano (2000) has explored how African-American college students experience and respond to racial microaggressions in both academic and social spaces within university settings through focus group interviews. Julie Minikel-Lacocque (2012) conducted a collective case study exploring Latino/a students" experiences of "subtle" racism as they transitioned from high school to a predominantly White university. Elsewhere, research has examined the ways in which educators do or do not recognize and respond to microaggressions in the classroom and the effectiveness or ineffectiveness of various responses (Boysen, 2012; Sue et al., 2009; Sue et al., 2007). Additionally, the impact of racial microaggressions upon faculty of color has been explored (Cartwright, Washington \& McConnell, 2009; Constantine, Smith \& Owens, 2008).

Nadal and colleagues (2011) proposed a theoretical taxonomy on sexual orientation and transgender microaggressions, delineating eight categories of microaggressions that may target LGBT persons: 1. Use of heterosexist and transphobic terminology occurs when someone uses derogatory heterosexist language toward LGBT persons (e.g., saying words like "faggot" or "dyke," an employer refusing to use individuals' preferred gender pronouns, or people using phrases like "That's so gay!"); 2. Endorsement of heteronormative or gender normative culture/behaviors transpires when an LGBT person is expected to act or be heterosexual or gender conforming. For instance, a parent forcing her or his child to dress according to birth sex; 3) Assumption of universal LGBT experience occurs when heterosexual people assume that all LGBT persons are the same (e.g., stereotyping all gay men to be interested in fashion or assuming all lesbian women like to ride motorcycles); 4) Exoticization microaggressions take place when LGBT people are dehumanized or treated as objects. This can be exemplified by the widespread production and consumption of pornography with lesbian imagery intended for heterosexual men; 5) Discomfort/disapproval of LGBT experience occurs when LGBT people are treated with disrespect and criticism, such as when a stranger stares at an affectionate same sex couple with disgust; 6) Denial of societal heterosexism or transphobia transpires when people deny that heterosexism and homophobia exist; 7) Assumption of sexual pathology/abnormality microaggressions come about when heterosexual or cisgender people over-sexualize LGBT persons and consider them as sexual deviants. For example, many people may assume that all gay men have HIV/AIDS or that transgender women are sex workers; 8) Finally, denial of individual heterosexism/transphobia occurs when non- LGBT people deny their own heterosexist and transgender biases and prejudice (Nadal, 2011).

More recently, scholars have begun looking at the intersectional nature of microaggressions against people with multiple marginalized identities. For example, Lewis, Mendenhall, Harwood \& Huntt (2013) explored the strategies Black women college students use to cope with and respond to microaggressions based on the intersection of one's race and gender. Both Nadal (2012) and Balsam, Molina, Beadnell, Simoni \& Walters (2011) have looked at microaggressions perpetrated against LGBTQ people of color at the intersection of race, gender identity, and sexual orientation. Balsam et al. (2011) generated an LGBTQ People of Color Microaggression Scale, an 18-item self-report scale assessing the unique types of microaggressions experienced by ethnic minority LGBTQ adults. Three subscales are embedded within the inventory: 1) Racism in LGBT Communities, 2) Heterosexism in Racial/Ethnic Minority Communities, and 3) Racism in Dating/Close Relationships (Balsam et al., 2011).

To date, we have seen no single article looking at microaggressions within Social Work education. In this article, the authors used observed statements and in-class exchanges to identify and analyze the types of microaggressions specific to social work graduate education. These comments (from students to students or student to faculty) generate a wealth of information about the diverse views, values and perspectives of those educating and being educated about intersectionality, oppression, power, and privilege. Strategies for enhancing critical consciousness and navigating transformative dialogues beyond basic course content for professors, students, and the social work climate are provided.

\section{Methods}

The present study utilized auto-ethnographies and observation based, qualitative methods to explore instructors' experiences of microaggressions occurring in social work classrooms. The instructors individually observed the microaggression exchanges in the course of teaching MSW (Master of Social Work) courses including Human Behavior in the Social Environment, Research, Practice and Policy classes over the course of two years. Instructors logged their experiences via journaling. The research team consisted of three Masters in Social Work instructors in a public university setting. These microaggressive statements were foundation and concentration level MSW students taking courses with the researchers. Microaggressive comments were made spontaneously by the students within the 
context of classroom dialogues. The researchers were interested in examining how the social work environment provided a context for microaggressions and how the climate was impacted by the responses and management (or lack of management) of the microaggressions.

\subsection{Procedure}

Each of the researchers generated and shared an independent list of microaggressions they observed or experienced within their social work classrooms. A composite list was developed from the data. From this composite list, the researchers independently analyzed the data, utilizing thematic analysis to "identify, analyze, and report patterns within the data" (Braun \& Clark, 2006, p. 79). Then the researchers met as a group, to review the themes, identify common categories and label the categories based on themes (Yosso, Smith, Ceja \& Solorzano, 2009). This discussion assisted in developing consensus regarding the broader domains and identifying prominent themes underscoring each domain.

\section{Findings}

The findings include direct quotes and microaggression themes identified from each instructor's individual and collective experiences teaching in a graduate social work department in a public university. These themes can be characterized by three broad domains: Racial microaggressions, LGBTQ microaggressions and Interstitial spaces microaggressions. Within each domain, specific themes are outlined to address how they appeared to impact the recipient, how they impacted the researcher and the potentially larger impact on the MSW program.

\subsection{Racial Microaggressions}

\subsubsection{Anti-affirmative Action}

A commonly observed theme within the racial microaggression domain was anti-affirmative action. Many microaggressions carried the implication that resources provided to promote equity for marginalized students were unnecessary or excessive. While it appears that the students and faculty perpetrating the microaggressions were not intending to offend the recipient(s) of the comment, defensiveness or denial following reactions by the recipient only reinforced the disempowering, disaffirming message. Typically, these comments were expressed by White students when comparing the opportunities of students of color with the opportunities of White students. While social work instruction focuses on increased sensitivity to visible and invisible diversity factors and awareness of power and privilege dynamics, it speaks volumes that despite conceptual knowledge, students continue to blindly judge each other by visible identity characteristics. Further, the judgment of these characteristics does not include consideration of power and privilege dynamics and historical factors contributing to disparate access to higher education and success within higher educational settings. Some of the statements included: "It's not fair that there are so many funding opportunities for students of color. What about the rest of us?" "Students of color get special treatment in this program." "Why do some agencies only hire diverse people? Isn't that going to make people that are not a person of color feel discriminated against and wouldn't they be the minority in that situation?"

\subsubsection{Colorblindness}

Another area in which microaggressions within social work classrooms proliferate is in regards to colorblindness (also known as "one love" or "we're all human"). Any group can deliver microaggressions, however, the most painful ones occur between those with power and those who are disempowered (Sue, et al, 2009). Those who commit microaggressions frequently do so unintentionally, highlighting the ambiguity inherent to microaggressions because of the differing perspectives of the transgressor and recipient (Boysen, 2012). Because microaggressions are typically invisible to the perpetrator, individuals who see themselves as decent, unbiased human beings struggle to believe that they have biased racial, sexual or gendered beliefs or that they might engage in discriminatory behaviors (Sue, et al, 2007). Neville, Spanierman and Doan (2006) assert that the colorblindness ideology of race shouldn't matter is often confused with race doesn't matter. Students and faculty who perpetuate this perspective often pay homage to diversity related differences, but deny the impact of privilege by claiming solidarity and unity. For the recipients of these microaggressions, it can be confusing to navigate the perpetrator's acknowledgement of diversity with their renunciation of privilege. Similar to the comments made suggesting anti-affirmative action, colorblind statements are recurrently made by White students and faculty, and place the receiving parties in the position of defending their subordinated experience. As a result, an unfortunate consequence of these declarations is the silencing of the marginalized recipient(s). Further, a colorblind perspective has significant, detrimental implications to the social work milieu; Atwater (2008) indicates that colorblind ideologies may hinder students' critical thinking skills and inadvertently impair their cognitive growth. Examples of colorblindness commentary include: "I feel like because I'm not a minority I shouldn't be made to feel bad about my accomplishments and my parents' 
accomplishments... I mean my parents' have dealt with the same challenges that minority students have had to deal with...like - substance abuse - unemployment and mental health issues." "This article about microaggressions offends me. I don't see color, we're all human. I feel like this is creating conflict and division." "I wasn't raised to see color so to be forced to talk about it now in this class makes me feel uncomfortable."

\subsubsection{Presumed Incompetence}

An area observed primarily for faculty of color was presumed incompetence. The researchers observed that faculty of color had multiple, recurring experiences where students "forgot" their title or credentials or questioned their presence in the classroom. Navigating the intersections of race, gender, socioeconomic status and educational background/title requires identity negotiation to define and understand one's sense of self while interacting with others (Glenn, 2012). In university settings, patriarchal standards that reflect a White, male, heterosexual dominant narrative may serve as a context for institutional, systemic or environmental microaggressions. Yosso, Smith, Ceja and Solórzano (2009) describe campus climates where messages regarding language, physical environment, personal property, and the limited integration of diversity related curriculum are evidence of White, middle class culture, marginalizing, devaluing and alienating those with differing identities. Dovidio (2012) describes contemporary questioning of competence directed at faculty of color as less openly questioning, and more whispering or silent suspicion. Examples of presumed incompetence include: students asking faculty of color "Are you the teacher?" upon first meeting them in the classroom. An additional collective experience was calling the professor of color Mr./Ms. X or by first name instead of Dr. X, after being informed of the correct title several times.

\subsubsection{Reverse Racism or Special Treatment Associated with Dominant Culture Fragility}

Reverse racism or special treatment is a microaggression that is frequently mentioned in the literature. However, within this study, the researchers observed reverse racism or special treatment in conjunction with dominant culture fragility. Assertions in this category take a "you are oppressing me" stance while simultaneously implying vulnerability or a lack of safety. Again, the observations are consistent that the perpetrators of these microaggressions are typically visibly members of dominant groups, with those on the receiving end have visible indicators of marginalized statuses. What is significant about this subgrouping is that while this exchange is occurring, the individual perpetrating the microaggression continues to maintain higher levels privilege while declaring their fragility, both in the process of the exchange and in the larger environment. The ironic quality of this microaggression frequently curbs deeper exploration or critical dialogue which could potentially add depth to the discussion. The challenge is moderating the discrepancies between privileged worldviews that uphold White supremacy and subordinated worldviews characterized by experiences of oppression. Maintaining polarized positions of privilege or subordination have the potential to isolate or activate emotional responses that further polarize faculty and students rather than increase mutual understanding (Sue \& Constantine, 2007). However, social work training programs must be structured and facilitated in a manner that promotes inquiry and allows students to experience both discomfort and vulnerability (Sue, et al, 2007). The ensuing comments exhibit this complex dynamic: "Because I'm the only White student in this class I can argue that I'm experiencing microaggression by you all..." "I feel like I can't say anything because it will be perceived as racist because I'm White." "It's hard to talk about intersectionality in classes because I am White and everyone assumes I have privilege all the time. I have been though a lot too, and no one cares about or recognizes that." "This seems like a lot of stuff to remember so that we don't offend anyone or make them feel uncomfortable... is it ever okay to not be so PC as a social worker?"

\subsubsection{Racism without Racists}

A final subgroup within the domain of Racial Microaggressions is racism without racists (or "Get Over-it") (Bonilla-Silva, 2006). Within this category, racism is acknowledged as an elusive, nebulous force, but the implication is that the perpetrator should be exempt from responsibility for racism, discrimination or privilege. Further, a corollary insinuation is a "that-was-then-this-is-now" perspective, which presumes that marginalized groups should "get over" their feelings about insubordination because it is ancient history. According to Brown and Perry (2011), many privileged individuals find it hard to acknowledge that racism and oppression still exist; thus, it is imperative that students accept accountability for their roles in maintaining the status quo and empower themselves and others to challenge systems of oppression (p. 2). For White students, this refers to an understanding of their Whiteness as a racial identity not only because of privilege, but also because of the coercive manner in which White elites constructed and maintained a racial hierarchy that allowed some to benefit from Whiteness while others remain perpetually removed (Casey, 2011, p. 6).

The process of developing critical consciousness necessitates self-awareness and recognition of the implications of power and privilege. Students must learn to deconstruct, examine and change their beliefs and attitudes (Brown \& 
Perry, 2011). The privilege to see oneself as raced, gendered, or sexualized and move comfortably and successfully through the world without recognizing privilege is a key aspect of privilege. The gaps between ignorance, self-awareness and humility are a breeding ground for microaggressions. Students comments include: "So, when working with clients of color should I automatically assume that they see me as the White oppressor--shouldn't they be able to move past that?" "I feel like I can't say anything because it will be perceived as racist because I'm White" "I don't mind talking about White privilege, but I don't feel comfortable talking about White supremacy. That's just so harsh. It's not like we are the KKK or anything."

\subsection{LGBTQ Microaggressions}

\subsubsection{Value System- Religious Beliefs}

Resistance to engaging material related to LGBTQ communities within the social work classroom commonly takes the form of personal values and religious freedom arguments. This occurs on both individual and broad scale levels. Students within general social work programs have gone so far as to file lawsuits against their Social Work programs for violation of religious freedom when programs refused to honor their requested exemption from working with LGBTQ communities. Some faith based social work programs have also upheld practices, such as conversion therapy, that are widely condemned for their harmfulness to LGBTQ communities. Within our own classrooms, the authors have heard microaggressive statements such as "I feel like I am denying my religious beliefs by accepting someone's homosexual lifestyle... I mean -I can't tell someone what to do but I can also disagree with it if I want."

A related phenomenon is the idea that because engaging in conversations about LGBTQ communities necessarily centers conversations about sexual orientation and gender identity - which often gets conflated with simply talking about sex - it is inappropriate for certain settings, or violates "family friendly" sensibilities. This has emerged in the classroom when discussing comprehensive sex education that is inclusive of LGBTQ communities, in the form of comments such as "I don't care really how people chose to live their life-I only have a problem when they try to teach my children in elementary school about sexual orientation and being gay... what if that's not something I want to teach my kids about at that time-I just feel that they are too young for all that stuff..."

\subsubsection{Assumption of Sexual Deviance/Pedophilia/Predatory}

The authors have additionally repeatedly observed an undergirding trope of presumed sexual deviance and/or pedophilia in classroom conversations regarding social work practice with LGBTQ communities. This insinuates an association of same-sex attraction and/or non -gender normative expressions and identities with predatory or criminal sexual practices. Another facet of this narrative is a belief that people are LGBTQ because of they have been sexually abused. For example, one author observed a student, upon hearing that a guest speaker was a sex offender, ask the speaker "Were you gay before you were sexually abused?" Do you think that relates to your being a sex offender at all?" Another manifestation of this predatorializing attitude is the charge of aggression or presumed unwanted attraction. For example, one author observed a student saying "I want to support gay women but they are just so aggressive in their approach. I tried to be an ally in college, but gay women just kept trying to get me to turn gay."

\subsubsection{Silence, Avoidance or Distance}

Another form of resistance to material pertaining to practice with LGBTQ communities are distancing techniques. Distancing techniques may take the form of silence or avoidance and are often a signifier of discomfort. For example, a student commented "I don't mind what people do. You can sleep with whoever you want but there are plenty of clients that need to be seen. I don't have to see all of them. I will refer gay clients out." Sometimes people simply succumb to silence in the midst of their discomfort, which is exemplified by statements like the following: "I worked with my first homosexual family and it felt weird because I didn't know what to say," and "Sometimes, because I don't know what to say (I don't want to offend anyone) I just decide not to ask them any questions at all about their sexuality." On occasion, this discomfort may be projected onto the client or classmate with an LGBTQ identity: "I feel like if I keep talking about a person's race or sexuality then I'm creating unsettling feelings for that person - isn't it best to not bring it up unless they bring it up?" This places the onus for relieving the discomfort on the member of the targeted group.

\subsubsection{LGBTQ Non-Affirmation}

LGBTQ non-affirmation is another category of microaggressions targeting LGBTQ communities. This consists of comments or gestures that are subtly undermining of community values or norms. An example is a student who asked: "Why does the gay community need all of the letters...isn't that creating division within the community by referring to them as L.G.B.T.?" Another example of LGBTQ non-affirmation is superimposing one's own 
sensibilities about the meaning of language over what's been expressed as preferable by a member of the LGBTQ community; for example, the student who said "In my time, it was derogatory to call someone queer. I don't know why any proud person would use that word to refer to themselves."

\subsubsection{Misgendering}

Misgendering is a common microaggression perpetrated against transgender, genderqueer, and other people who don't fall neatly within the gender binary. In the classroom, this may take the form of refusing or forgetting to refer to people by their preferred gender pronoun or preferred name. It can also be simply forgetting or not knowing to ask people their preferred gender pronouns. It may also take the form of referring to people collectively as an assigned gender (ie. "How are you ladies doing with this assignment?"). An example of a misgendering microaggression is exemplified in the following statement made by a student: "When I was working with a transgender man I wanted to ask her what was her real name before she decided to change into a man." If this is happening in the classroom, it is likely also happening in the practice arena.

\subsection{Interstitial Spaces of Microaggressions}

\subsubsection{Multiracial Microaggressions}

Students within the classroom setting can experience multiracial microaggressions which can be seen within the same racial group (i.e. also known as intra-racial microaggressions). This is when someone of the same and/or sharing some of the same racial identity makes subtle statements and/or remarks about other another person's identity. For example, an individual being told that they are not enough of one racial group because they are of multiracial descent; and therefore cannot speak on behalf of the racial experience of the group nor their own experience. Individuals of the same racial group can sometimes try to coerce each other into using their own label (e.g. blackness) in the name of their label being the "most right". This can be viewed as policing of one's identity. An example of policing identity would be, "I feel like you are not "really down." Maybe it's because you are only half Black." This implies that the person of multiracial descent is not one of "them" and is therefore viewed as an outsider who cannot identify with the experience and lifestyle of the group as a whole.

\subsubsection{Intersections of Race, Sexual Orientation and Gender Identity Microaggressions}

It is also common for LGBTQ students of color to encounter microaggressions at the intersection of race, sexual orientation and gender identity. Intersectionality becomes especially complex when dealing with interactions between people who experience different sets of oppression and thus are simultaneously more privileged and less privileged than each other. For example, White LGBTQ students generally experience more privilege than LGBTQ students of color. Examples of intersectional microaggressions perpetrated against LGBTQ students of color include a student who stated: "You know that Black and Latino voters are responsible for Prop 8 passing." This statement which refers to the passing of anti-Marriage ballot initiative Proposition 8 - reinforces the common trap of framing racial and LGBTQ justice as inherently at odds. This false dichotomy no only jeopardizes important alliances, but it fails to acknowledge the experiences of people who claim identities in both communities. Another example of an intersectional microaggression is the comment: "How can a transgender black woman say that she is sexually attracted to a white woman... he should have just stayed a man and dated outside of his race?" This statement implies that the individual must be "confused".

\subsubsection{Tokenization as a Microaggression}

There are also encounters that happen in the classroom that rarely get discussed and can be viewed as microaggressions in the form of tokenization. Tokenization can be defined as an individual involuntarily being placed to serve as a visible representation of the oppressed group and/or chosen to speak on behalf of the experience and feelings of the oppressed group (Haskins, Whitfield-Williams, et al., 2013). Students who attend school in predominantly White college/university often find their experiences challenging and they may encounter tokenization, wherein they stand out as members of a minority group who are visibly different from those in the majority. An example of this would be, "Do you mind professor if I don't share as much in this class because I am the only gay student and I do not feel comfortable serving as the voice for all gay people." In addition, "It makes sense professor that you would work with the African American community in South Los Angeles because you are an African American and there is a need for men like you there."

\subsubsection{Out Dated Terminology}

Lastly, when students utilize out of date terminology and/or fail to utilize up-to-date nondiscriminatory/derogatory terms - this is experienced as a microaggression. An example of this would be, "I think homosexual people should 
get the same rights as heterosexual people" and also "I feel like I am denying my religious beliefs by accepting someone's homosexual lifestyle... I mean - I can't tell someone what to do but I can also disagree with it if I want."

\section{Discussion}

\subsection{Pedagogical Tactics and Strategies}

Contemporary racism, homophobia, and transphobia have evolved from overt forms of discrimination to more disguised, covert presentations (Sue, et al, 2007). Despite their subtlety, microaggressions can have a deleterious and cumulative effect on the psychological, emotional, health, relational and academic functioning of students of color and LGBTQ students. They have been found to act as a stressor on psychological and physical health, negatively influencing students' perception of campus climates, and hampering the ability to cognitively process information (Bair \& Steele, 2010; Boysen, 2012; Sue, et al, 2008). Students who experience privilege in one or more identity categories may also experience detrimental consequences by unintentionally engaging in microaggressions. Remaining oblivious to the impact of microaggressions has been found to lower empathic ability, lessen compassion and dim perceptual awareness (Spanierman, Armstrong, Poteat \& Beer, 2006). Because all of these consequences can adversely impact the efficacy, well-being and sustainability of social work professionals, management of microaggressions is key in social work education. The responsibility for classroom management and modeling responses congruent with social work values falls primarily on the academic instructor. Several key recommendations for addressing microaggressions within social work education are as follows:

1. Academic faculty would benefit from gaining training and experience with facilitating complex and challenging dialogues on power and privilege. If faculty members are to become comfortable discussing and teaching about race, sexual orientation, gender identity and micro-aggressions, it is imperative that the trainings include not just intellectual and cognitive but experiential exercises. It is also important to consider that the success of the dialogue depends on the cultural sensitivities, comfort and awareness of the faculty member leading the discussion. One must be able to facilitate dialogues and manage discomfort in the classroom by creating a safe space to do so. When challenging dialogues ensues, faculty members must be able to do an internal check in in order to identify and manage anxiety and discomfort.

2. Academic faculty need to be honest with themselves that they are not exempt from having biases or strong feelings and reactions to discussions centered around race, sexual orientation, gender identity, and privilege. In addition, faculty must be aware of racial disparities, injustices/inequalities surrounding people of color as well as those faced by LGBTQ students. It is their duty and responsibility to be in the know about recent and historic trends and struggles. Further, White faculty must be willing to address their "Whiteness" and positions of power and privilege to promote interracial and intra-racial dialogue, and assist students with challenging dialogues that may create discomfort. Similarly, heterosexual and cisgender faculty need to be aware of the nature and impact of microaggressions perpetrated against LGBTQ students and faculty. Moreover, developing a nuanced understanding of interlocking systems of oppression and interstitial spaces can prove invaluable in navigating some of the common pitfalls of social justice dialogues in the classroom.

3. Academic faculty must be aware that students might be holding back due to fear that their grade may suffer as a result of being candid. Conversely, students might feel vulnerable due to being the only identified marginalized person in the class and may refrain from sharing due to not wanting to be the representative for that subgroup. It is important for faculty members to validate "lived experiences" regardless of their personal perspective. Disclosures of experience and an emphasis on experiential aspects of real life situations can open up dialogue with other students, creating opportunities for growth.

4. Academic faculty should begin by building a foundation and basis for having dialogue around race, sexual orientation, and gender identity by creating a classroom culture and climate of tolerance and respect. This can be facilitated by creating a reflective classroom contract in collaboration with students, or through some other means of establishing guidelines for respectful dialogue and a mechanism for accountability. It is equally important for faculty to prepare themselves for ignorance, not assuming or expecting that students will be receptive.

5. It is vital that academic faculty seek support and consultation outside of the classroom setting. There should be a diverse pool of faculty and staff (i.e. both intra and inter -discipline) that serve as a consultation team to give/receive feedback; to have accountability; and to learn from colleagues. Team teaching may be 
a viable option that allows for immediate feedback, consistent support and ongoing opportunities for skill development.

\section{Conclusion}

This study examined microaggressions specific to social work graduate education. The findings support the ongoing need for social justice education to expand beyond diversity to encompass the complexities of intersectionality, microaggressions, power and privilege. It is critical for students to learn academic concepts and practice skills that promote social justice in the classroom and the field to expand their understanding and management of microaggressions. Unchecked microaggressions have the potential to harm individuals, the graduate social work milieu and vulnerable client populations. Social work educators must be proactive engagers in addressing, discussing, sustaining and maintaining challenging dialogue around microaggressions expressed in the classroom. These findings highlight the need for social work educators to develop the skills to initiate difficult dialogues, be accountable for self-reflection and model authenticity when facilitating dialogue around microaggressions in social work education.

\section{References}

Atwater, S. A. C. (2008). Waking up to difference: Teachers, color-blindness, and the effects on students of color. Journal of Instructional Psychology, 35(3), 246.

Bair, A. N., \& Steele, J. R. (2010). Examining the consequences of exposure to racism for the executive functioning of Black students. Journal of Experimental Social Psychology, 46, 127-132. https://doi.org/10.1016/j.jesp.2009.08.016

Balsam, K. F., Molina, Y., Beadnell, B., Simoni, J., \& Walters, K. (2011). Measuring multiple minority stress: The LGBTQ people of color microaggressions scale. Cultural Diversity and Ethnic Minority Psychology, 17(2), 163-174. https://doi.org/10.1037/a0023244

Boysen, G. A. (2012). Teacher and student perceptions of microaggressions in college classrooms. College Teaching, 60, 122-129. https://doi.org/10.1080/87567555.2012.654831

Brown, A. L., \& Perry, D. (2011). First impressions: Developing critical consciousness in counselor training programs. Journal of Feminist Family Therapy, 23, 1-18. https://doi.org/10.1080/08952833.2011.548699

Cartwright, B. Y., Washington, R. D., \& McConnell, L. R. (2009). Examining racial microaggressions in rehabilitation counselor education. Rehabilitation Education, 23(3-4), 3-4. https://doi.org/10.1891/088970109805029996

Casey, Z. A. (2011). The fight in my classroom: A story of intersectionality in practitioner research. i.e.: inquiry in education, 2(1), Article 3.

Constantine, M., Smith, L. R. R.M., \& Owens, D. (2008). Racial microaggressions against Black counseling and counseling psychology faculty: A central challenge in the multicultural counseling movement. Journal of Counseling and Development, 86(3), 348-355. https://doi.org/10.1002/j.1556-6678.2008.tb00519.x

Dovidio, J. F. (2012). Introduction. In Presumed Incompetent: The Intersections of Race and Class for Women in Academia. The University Press of Colorado: The Association of American University Presses (Edited by Gutierrez y Muhs, G., Flores Niemann, Y., Gonzalez, C. G., \& Harris, A. P.)

Glenn, C. L. (2012). Stepping In and Stepping Out. In Presumed Incompetent: The Intersections of Race and Class for Women in Academia. The University Press of Colorado: The Association of American University Presses (Edited by Gutierrez y Muhs, G., Flores Niemann, Y., Gonzalez, C. G., \& Harris, A. P.)

Haskins, N., Whitfield-Williams, M., Shillingford, M. A., Singh, A., Moxley, R., \& Ofauni, C. (2013). The experiences of black master's counseling students: A phenomenological inquiry. Counselor Education and Supervision, 52(3), 162-178. https://doi.org/10.1002/j.1556-6978.2013.00035.x

Lewis, J. A., Mendenhall, R., Harwood, S. A., \& Huntt, M. B. (2013). Coping with gendered racial microaggressions among Black women college students. Journal of African American Studies, 17(1), 51-73. https://doi.org/10.1007/s12111-012-9219-0

Minikel-Lacocque, J. (2012). Racism, College, and the Power of Words Racial Microaggressions Reconsidered. American Educational Research Journal. 
Nadal, K. L., Issa, M., Leon, J., Meterko, V., Wideman, M., \& Wong, Y. (2011). Sexual orientation microaggressions: Psychological impacts on lesbian, gay, and bisexual youth. Journal of LGBT.

Nadal, K., Skolnik, A., \& Wong, Y. (2012). Interpersonal and systemic microaggressions toward transgender people: Implications for counseling. Journal of LGBT Issues in Counseling, 6, 55-82. https://doi.org/10.1080/15538605.2012.648583

National Association of Social Workers (NASW). (2015). Retrieved April 25, 2015, from https://www.socialworkers.org/pressroom/features/issue/peace.asp

Neville, H., Spanierman, L., \& Doan, B. T. (2006). Exploring the association between color-blind racial ideology and multicultural counseling competencies. Cultural Diversity and Ethnic Minority Psychology, 12(2), 275. https://doi.org/10.1037/1099-9809.12.2.275

Pierce, C. M., Carew, J. V., Pierce-Gonzalez, D., \& Wills, D. (1977). An Experiment in Racism TV Commercials. Education and Urban Society, 10(1), 61-87. https://doi.org/10.1177/001312457701000105

Solorzano, D., Ceja, M., \& Yosso, T. (2000). Critical race theory, racial microaggressions, and campus racial climate: The experiences of African American college students. Journal of Negro Education, 60-73.

Smith, W. A. (2004). Black faculty coping with racial battle fatigue: The campus racial climate in a post-civil rights era. In D. Cleveland (Ed.), A long way to go: Conversations about race by African American faculty and graduate students of predominantly White institutions (p. 171-190). New York: Peter Lang.

Spanierman, L. B., Armstrong, P. I., Poteat, V. P., \& Beer, A. M. (2006). Psychosocial costs of racism to Whites: Exploring patterns through cluster analysis. Journal of Counseling Psychology, 53, 434-441. https://doi.org/10.1037/0022-0167.53.4.434

Sue, D. W. (2010). Microaggressions in Everyday Life: Race, Gender and Sexual Orientation. New Jersey: John Wiley \& Sons.

Sue, D. W., \& Constantine, M. G. (2007). Racial microaggressions as instigators of difficult dialogues on race: Implications for student affairs educators and students, College Student Affairs Journal, 26(2), 136-143.

Sue, D. W., Capodilupo, C. M., Torino, G. C., Bucceri, J. M., Holder, A. M. B., Nadal, K. L., \& Esquilin, M. (2007). Racial microaggressions in everyday life: Implications for clinical practice. American Psychologist, 62(4), 271-286. https://doi.org/10.1037/0003-066X.62.4.271

Sue, D. W., Lin, A. I., Torino, G. C., Capodilupo, C. M., \& Rivera, D. P. (2009). Racial microaggressions and difficult dialogues on race in the classroom. Cultural Diversity and Ethnic Minority Psychology, 15(2), 183-190. https://doi.org/10.1037/a0014191

Watt, S. K. (2007). Difficult dialogues, privilege and social justice: Uses of the privileged identity exploration (PIE) model in student affairs practice. College Student Affairs Journal, 25, 114-125.

Yosso, T. J., Smith, W. A., Ceja, M., \& Solórzano, D G. (2009). Critical race theory, racial microaggressions, and campus racial climate for Latina/o undergraduates. Harvard Educational Review, 79(4), 659-690. https://doi.org/10.17763/haer.79.4.m6867014157m7071 